\title{
Hardware Implementation of PID and ACO Based Wireless Heating System
}

\author{
Rajesh Singh ${ }^{1}$, Piyush Kuchhal ${ }^{2}$, M.S. Yadav ${ }^{3}$, Sushabhan Choudhury ${ }^{4}$, and Anita ${ }^{5}$ \\ 1.2.4.5 University of Petroleum and Energy Studies, Dehradun, India \\ ${ }^{3}$ Kurukshtera University, Kurukshetra, Haryana, India \\ ${ }^{1}$ rsingh@ddn.upes.ac.in ${ }^{3}$ schoudhury@ddn.upes.ac.in ${ }^{5}$ anita@ ddn.upes.ac.in
}

\begin{abstract}
In this paper a PID and ACO based wireless heating system is proposed. The heater node with temperature sensor senses the temperature of the room and compares it with set temperature for the system. The required temperature is set by RF remote control and the feedback signal generated by heater node generates the error signal to PID controller. The optimized value of $\mathrm{K}_{\mathrm{P}}, \mathrm{K}_{\mathrm{I}}, \mathrm{K}_{\mathrm{D}}$ are calculated by using ACO algorithm. The PID controller output data fed to the dimmer circuit to control the dimming level of heating system. In the proposed system upto $8.72 \%$ power can be saved in two hours with the experimental setup.
\end{abstract}

Keyword: ACO, Heater, MATLAB simulation, PID controller, RF remote, Zigbee

\section{Introduction}

A system is suggested which giving solution for indoor lightning is using chargeable photovoltaic cell which charges with daylight with the help of light sensor and motion sensor. The whole system is controlled by controller through wireless radio; it employs a feedback control algorithm to determine the dimming levels of the luminaires. Proposed prototype allows lifetime of $20 \mathrm{~h}$ in a complete dark environment [1] .Street lighting monitoring and control system by using JN5148 wireless module with dimming circuit is discussed. For vehicle detection two methods are proposed one using PIR sensor and another Doppler sensor, among which results of Doppler method are better [2]. Integrated system for street light control with combination of Zigbee and GPRS is proposed. It reduces the power consumption [3]. An ultra-low-power common-gate low noise amplifier (CG-LNA) is proposed for 2.4 GHz wireless sensor network (WSN) applications. The technique used is current reuse and active boosting. A prototype is developed using CMOS technology using on-wafer probing. Results show a gain of $14.7 \mathrm{~dB}$ and noise figure is $4.8 \mathrm{~dB}$ at $2.44 \mathrm{GHz}$ [4]. A wireless system for LED is developed in room and system performance is compared for two dimming techniques Pulse Width Modulation and Continuous Current Reduction and CCR is observed as more efficient technique. The system performance is assessed in terms of signal to noise ratio and bit error rate [5]. The performance of visible light for data transmission is observed. The system uses pulse width modulation for dimming and discrete multi-tone modulation for data transmission. By simulation of system it is observed that communication by visible light is only possible if the line rate of the dimming modulation is at least twice the frequency assigned to the largest multi-tone subcarrier frequency dimming and also results shows dimming does not affect data transmission if suitable demodulation technique is used [6]. A Zigbee with IR code learning to control home appliances in a room to reduce power consumption by control the dimming light is proposed. The room architecture is proposed which is controlled by IR remote control of any home appliance [7]. PSO can be implemented on the nonlinear, nondifferentiating able and multimode domain problem; it can be applied to find out optimization distance of WLAN base station. PSO is started with a group of random particles (solutions) and then searches and update optimum values [8]. The ACO algorithm is based on ant behaviour for food searching. Ant drops pheromone when travel from nest to food, and concentration of pheromone helps other ants to choose shortest and appropriate path [9].

Received: November $5^{\text {th }}, 2014$. Accepted: September $9^{\text {th }}, 2015$ DOI: 10.15676/ijeei.2015.7.3.4 


\section{Hardware development}

A. Remote Control

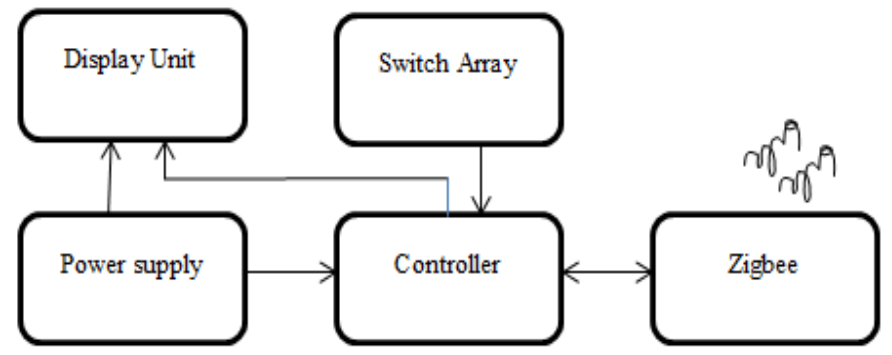

Figure 1. Remote Control

Figure 1 shows block diagram of remote, it is used to feed the input by user. It comprises of controller (Atmega8), display unit (LCD 16x2), switch array (array of push buttons), battery $(9 \mathrm{~V} / 200 \mathrm{mAh})$, Zigbee $(2.4 \mathrm{GHz})$. The required temperature is set with the switch array, and it will be displayed on display unit and transmitted to the heater node through Zigbee.

\section{B. Heater node}

Figure 2 shows block diagram of heater node, which comprises of heater (1KW), RTC (1307), EEPROM(24xx), dimmer(MOC3021+MOSFET), temperature sensor L35, controller (Atmega16), Zigbee and power supply (12V/1A adapter). It will receive the data from remote control and sensor node as well. By getting the information from remote control it will fix the required temperature. After some time when temperature reach to required value, PID controller and Ant Colony Optimization algorithm is applied on collected data from sensor nodes to provide stable temperature and at an optimized level in form of $\mathrm{K}_{\mathrm{P}}$ (proportional constant), $\mathrm{K}_{\mathrm{I}}$ (Integral constant), $\mathrm{K}_{\mathrm{D}}$ (Derivative constant ), the heater node will be set, as shown in Figure. 3 This process will be continued to maintain the required temperature value. This will be done with the help of temperature sensor and dimmer. Temperature sensor to check the exact room temperature and dimmer to control the level according to optimized value. RTC to provide exact time of temperature data received and EEPROM to store the data for further use.

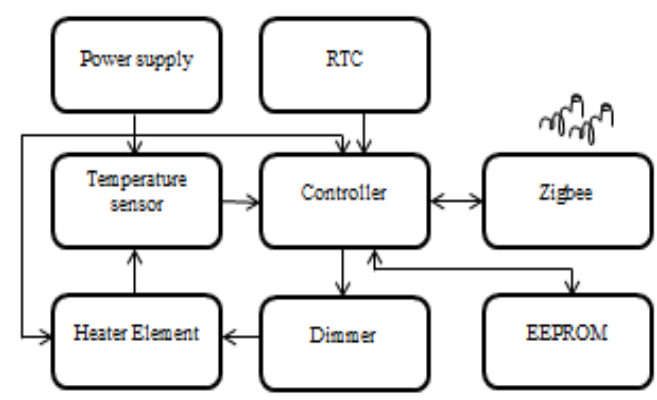

Figure 2. Heater node

Transfer function for heater element is given by equation (1)

$$
C(s)=\frac{e^{-T s}}{t s+1}
$$

Here

$\mathrm{T}=$ delay time

$\mathrm{t}=$ rise time 


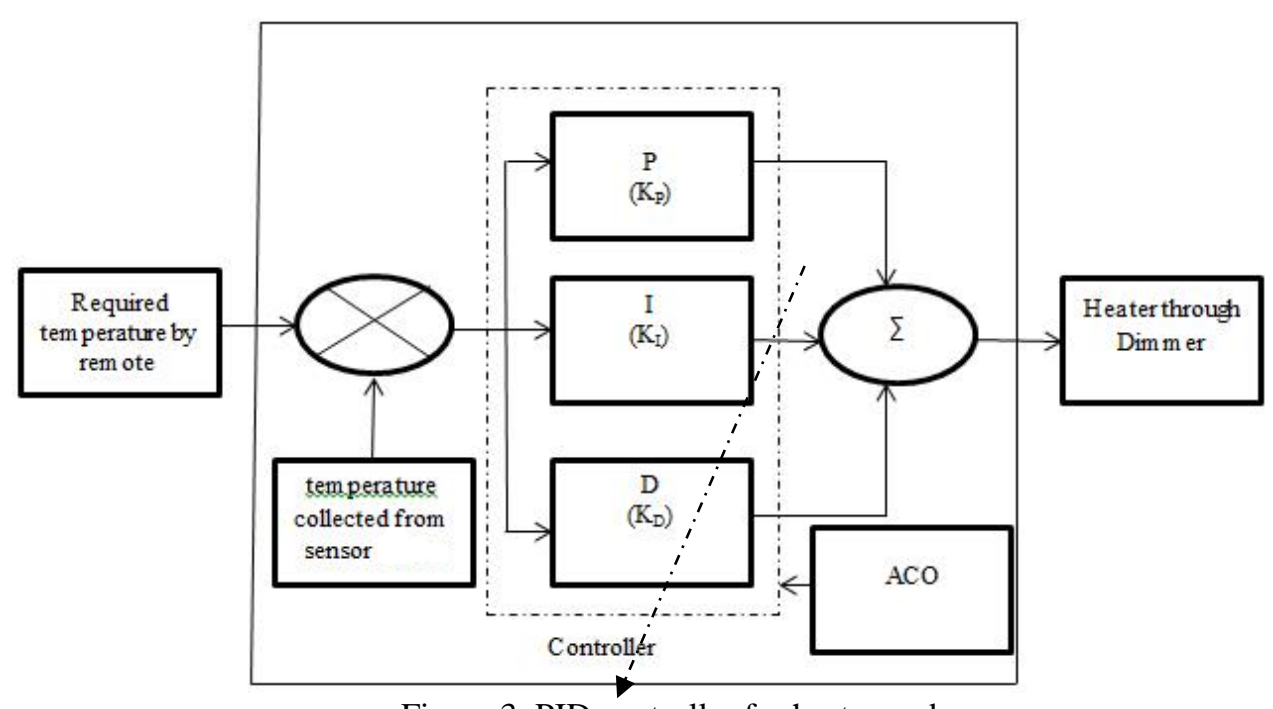

Figure 3. PID controller for heater node

\section{Software development}

PID controller is required to find out the best controller parameters like $K_{P}, K_{I}, K_{D}$ PID controllers are widely used in control industries due to its simple structure and simple to use. PID controller is tuned to obtain desired closed loop performance, based on the dynamic model of system and then implement the results using suitable platform to program the valid values.

The transfer function for PID controller is given by equation (2) as below:

$$
\mathrm{G}(\mathrm{s})=\mathrm{K}_{\mathrm{P}}+\mathrm{K}_{\mathrm{I}} / \mathrm{s}+\mathrm{K}_{\mathrm{D}} \mathrm{s}
$$

Where

$\mathrm{K}_{\mathrm{P}}$ - Proportional gain

$\mathrm{K}_{\mathrm{I}}$ - Integral gain

$\mathrm{K}_{\mathrm{D}}$-Derivative gain

A number of tuning methods are available for finding the controller parameters, the choice of method is also a big constraint, it basically depends upon the type of system which is to be controlled. A lot of computational steps are required to get valid tuned parameters to derive the system. To avoid computational complexity researchers are now using different optimizing techniques for this.

Genetic algorithm is one of the optimizing techniques to find out the optimized parameters without involvement of the computational complexity. The proposed system find out the optimized parameters by genetic algorithm with PID controller and then use them on the system with the help of ATMEGA controller.

ACO algorithm with PID controller

1. Initialize the algorithm parameters like number of iterations, number of ants, strength of pheromone and decay rate.

2. Initialize the values of $K_{P}, K_{I}$ and $K_{D}$ for PID controller

3. For each ant the transition probability is calculated

4. Incrementally builds a solution and local pheromone update

5. 5 Update the best solution

6. Update a global pheromone

7. Repeat the steps 3 to 6 until the maximum iteration is reached

8. Get the optimized values of $K_{P}, K_{I}$ and $K_{D}$ 
Digital Processor for implementation of ACO- PID

The processor employed for implementation of PID is the Atmega16. It is 8 bit microcontroller based on enhanced RISC architecture with 131 powerful instructions. Atmega16 can work on a maximum frequency of $16 \mathrm{MHz}$. ATmega16 has flash memory of 16 $\mathrm{KB}$, static RAM of $1 \mathrm{~KB}$ and EEPROM of 512 Bytes. It has $32 \mathrm{I} / \mathrm{O}$ (input/output) lines. It is supported by USART, ADC, Analog Comparator, SPI, JTAG etc. The following command set have been used for implementation of the PID

\#define Prop_GAIN 3.3921/*all GAIN values have been computed by ACO algorithm*/

\#define Int_GAIN 0.0285

\#define Der_GAIN -20.496

\#define_dt_0.5

int set_Temp $=0$, previous_error $=0$;

int error, feedback_Temp, output;

int Derivative_error $=0$, Integral_error $=0$;

previous_error $=$ set_Temp - feedback_Temp;

error $=$ set_Temp - feedback_Temp;

Integral_error $+=(\text { error })^{*} \_\mathrm{dt}$;

Derivative_error $=($ error - previous_error $) /$ dt;

output $=($ Prop_GAIN $*$ error $)+(\overline{I n t}$ _GAIN $*$ Integral_error $)+($ Der_GAIN * Derivative_error);

previous_error = error;

\section{Circuit diagram and proteus simulation}

Figure 4 shows circuit diagram of system comprising heater node and remote control. Figure 5 shows Proteus simulation model for the system, as simulation is done before hardware implementation to check accuracy and feasibility.

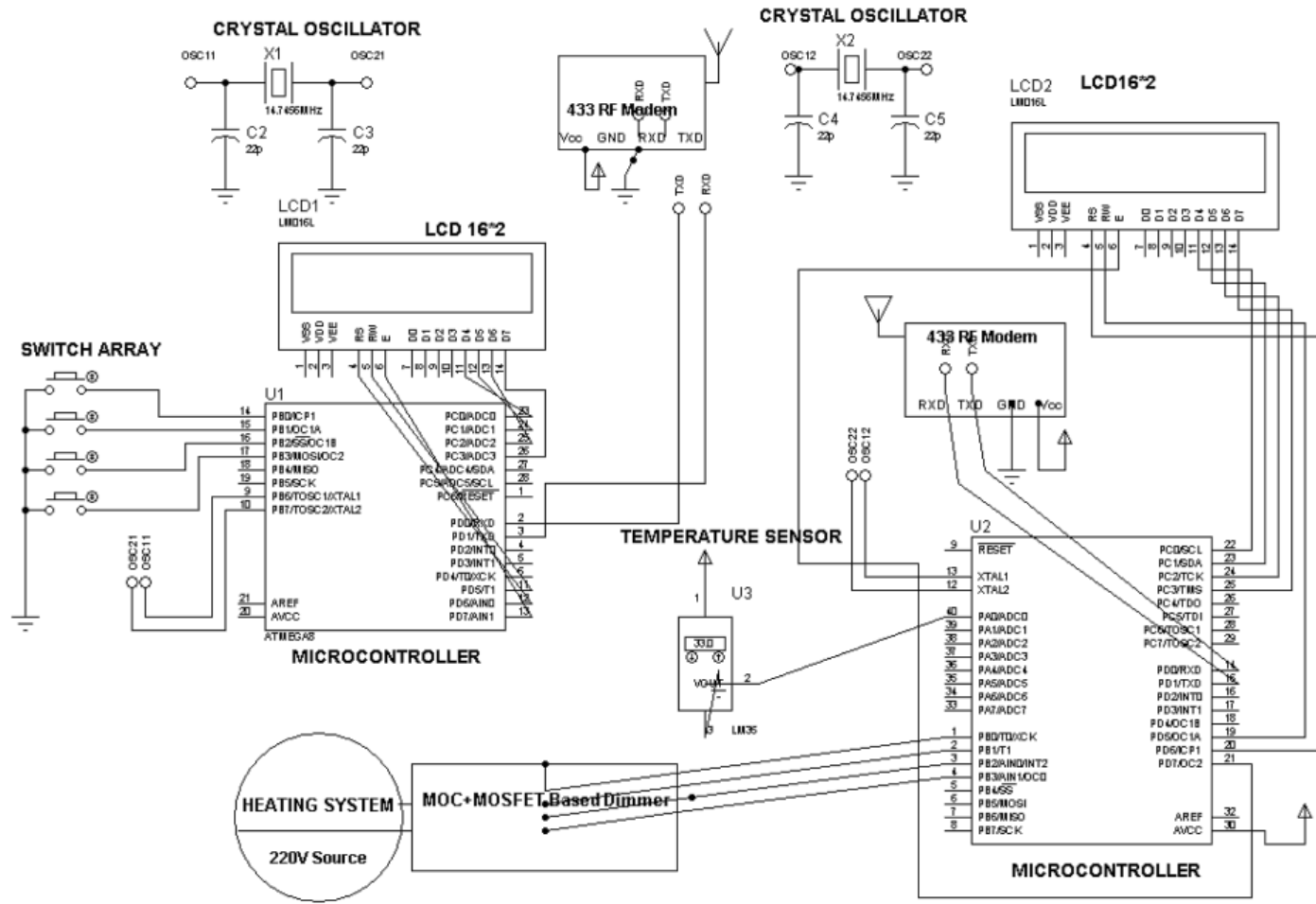

Figure 4. Circuit diagram of remote and Heater node 


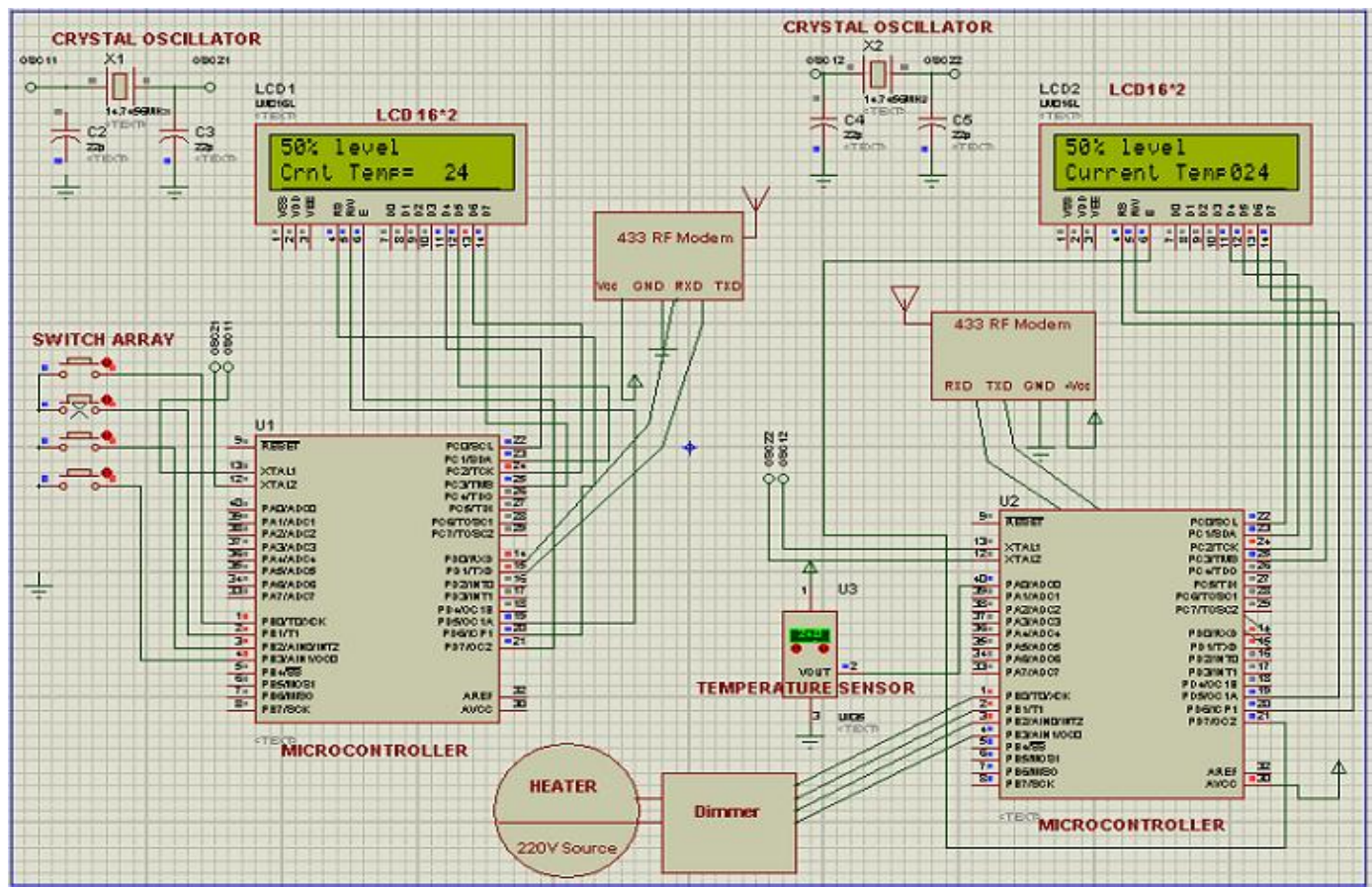

Figure 5. Proteus Simulation of remote and Heater node

\section{Implementation of PID and ACO}

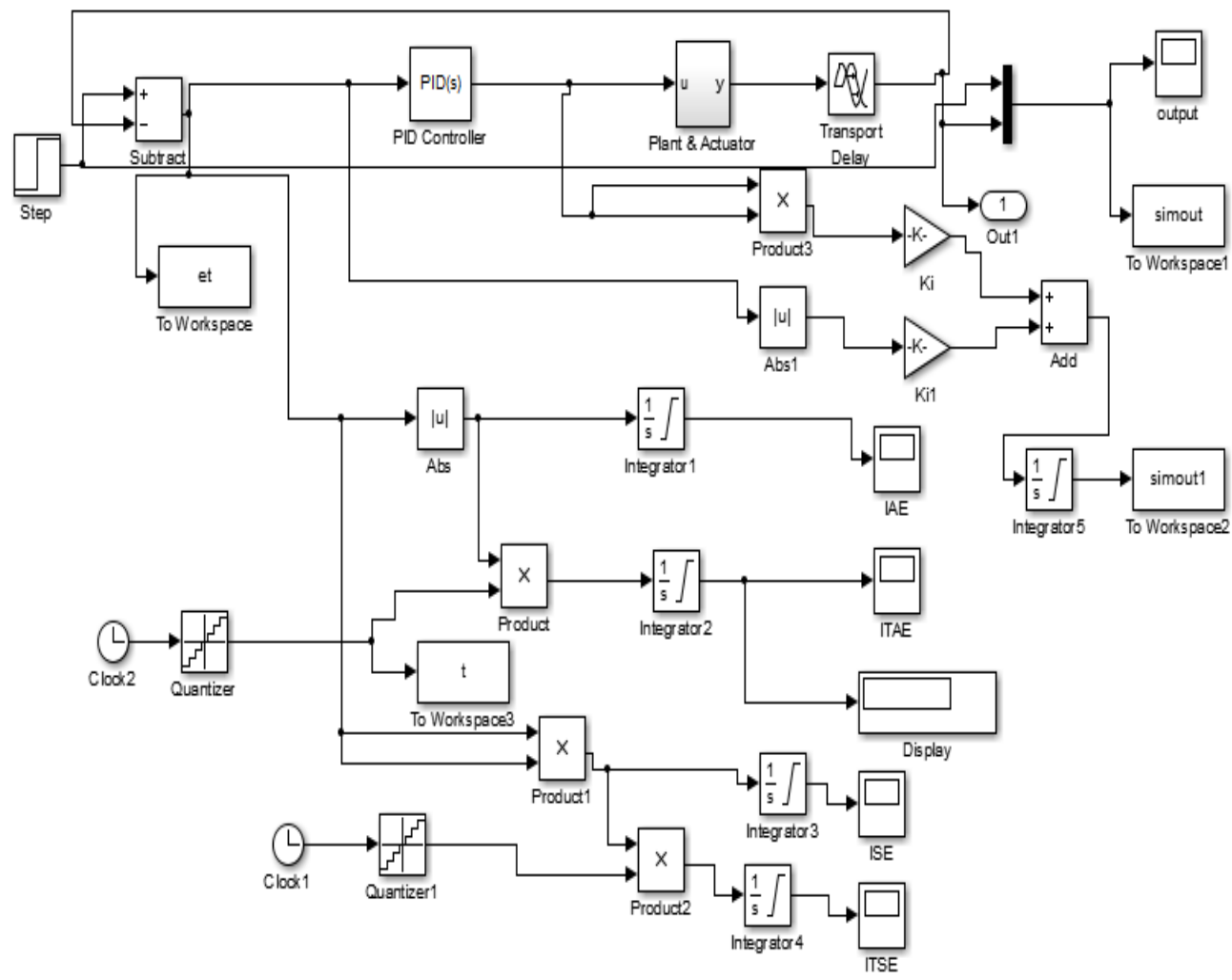

Figure. 6 MATLAB simulation for ACO-PID 
As shown in Figure.6 the simulation for PID and ACO has been done with MATLAB Simulink. First PID controller was realized with the MATLAB and M (Overshoot time), $T_{r}$ (Rising time) and $\mathrm{T}_{\mathrm{s}}$ (Settling time), $\mathrm{K}_{\mathrm{P}}, \mathrm{K}_{\mathrm{I}}, \mathrm{K}_{\mathrm{D}}$ were observed.

Then ACO was being implemented to measure optimized values $K_{P}, K_{I}, K_{D}$ and set the system by these values and comparative study has been done. Figure.7 shows MATLAB simulation results of ACO-PID.

Figure 8 shows bode plot results for the system

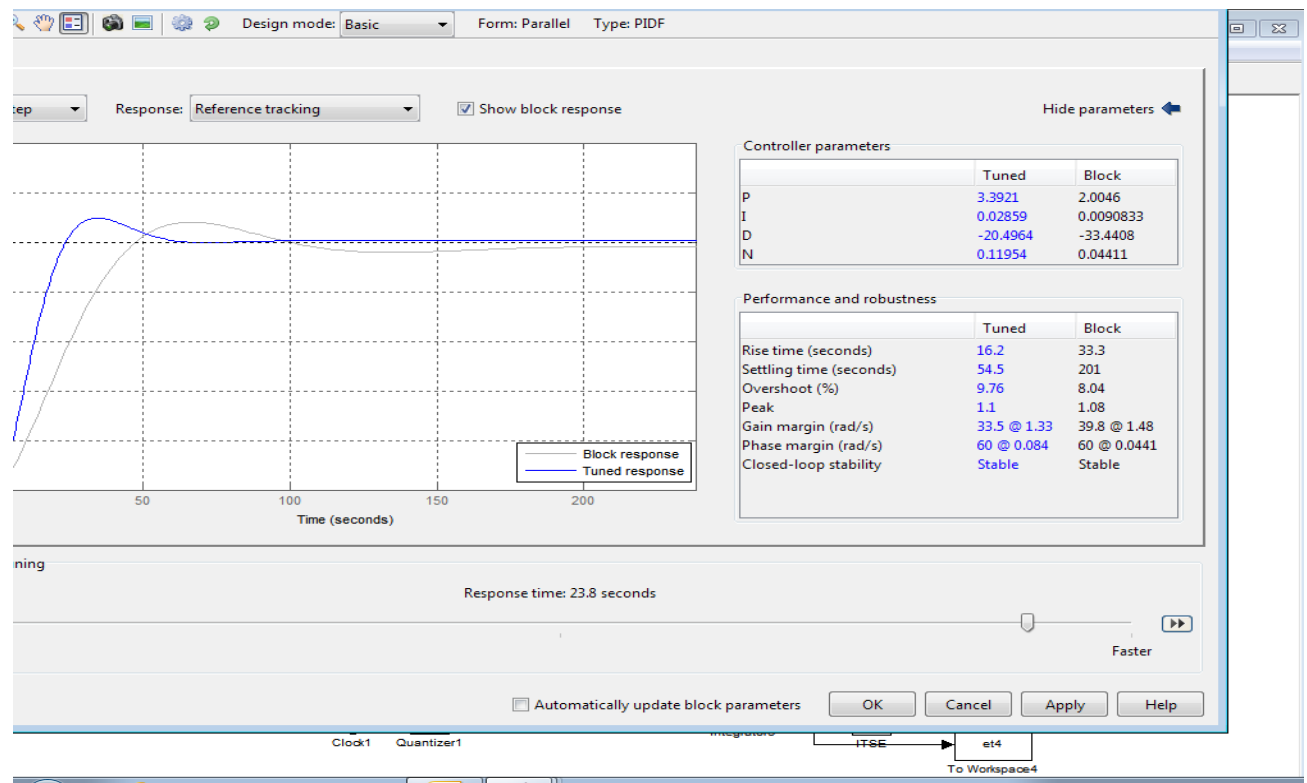

Figure.7 PID response with implementation of ACO

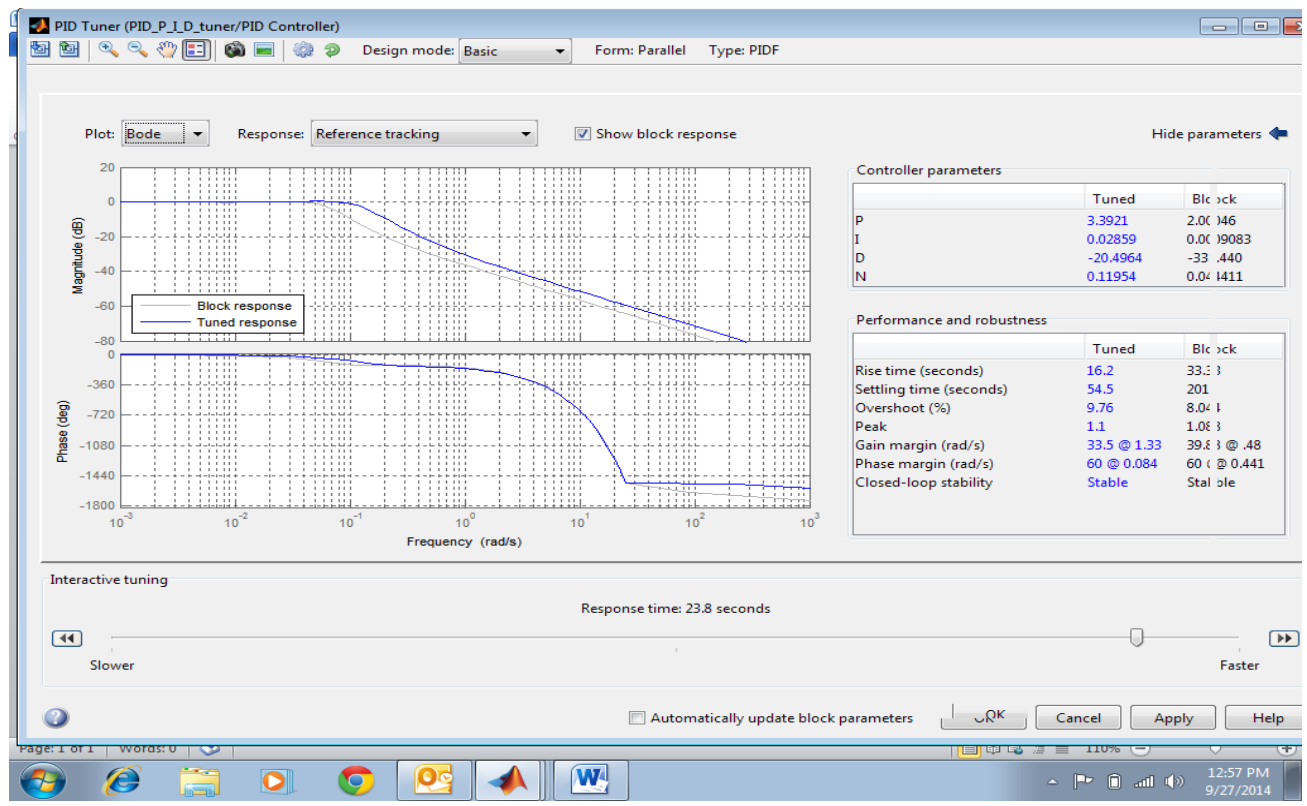

Figure 8. Bode Plot for ACO-PID controller 
Table 1. Comparative Analysis for PID and ACO-PID

\begin{tabular}{|c|c|c|}
\hline & PID & ACO-PID \\
\hline $\mathrm{K}_{\mathrm{P}}$ & 2.0046 & 3.3921 \\
\hline $\mathrm{K}_{\mathrm{I}}$ & 0.0090 & 0.0285 \\
\hline $\mathrm{K}_{\mathrm{D}}$ & -33.440 & -20.496 \\
\hline $\mathrm{M}$ & 6.77 & 9.21 \\
\hline $\mathrm{T}_{\mathrm{r}(\mathrm{sec})}$ & 33.3 & 16.2 \\
\hline $\mathrm{T}_{\mathrm{s}(\mathrm{sec})}$ & 201 & 54.5 \\
\hline
\end{tabular}

\section{Experimental set up}

Hardware has been implemented and controller was programmed with the optimized values $K_{p}, K_{I}$ and $K_{D}$ using ACO algorithm.Figure.9 shows developed remote control to set the required temperature and Figure.10 shows developed heater node having processing unit (Atmega16) which is programmed with optimized values of $\mathrm{K}_{P}, \mathrm{~K}_{\mathrm{I}}, \mathrm{K}_{\mathrm{D}}$

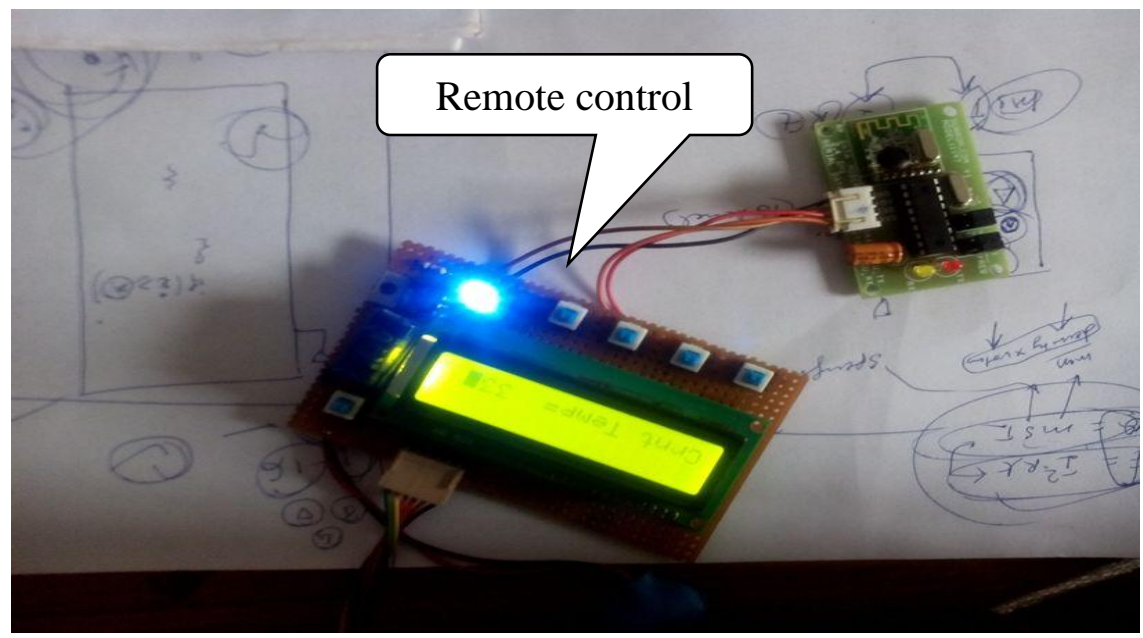

Figure 9. Snapshot of developed remote control

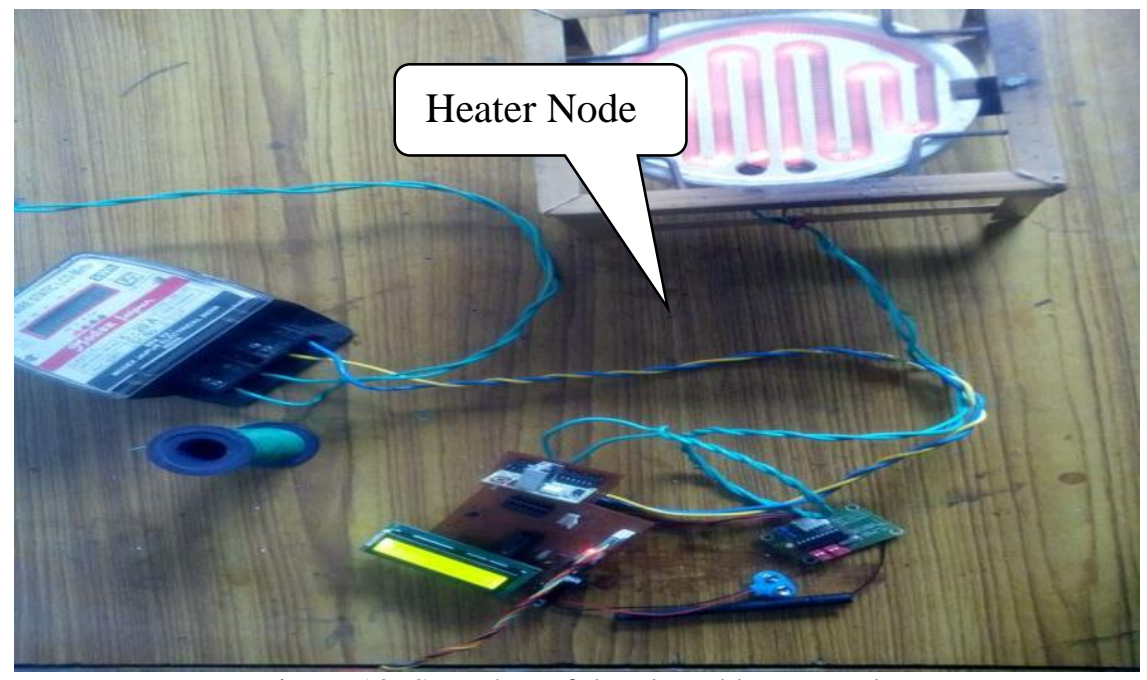

Figure 10. Snapshot of developed heater node 


\section{Results and discussion}

Table 2 shows the \% saving in power and maintenance of constant temperature of the test room after using the ACO algorithm. The wattage is measured by the energy meter. Four temperature sensors connected is used to collect temperature data form four corner of the room and send it to heater node to use it for controlling PID controller. The temperature collected by temperature sensors are feedback wirelessly to the heater node. The preset temperature from the user remote acts as the reference input for generating the error signal in closed loop. The data collected from the four sensors are averaged by the heater node and used as feedback signal. The so generated error signal is used to control the temperature of the room. It is observed that the test room is maintained at preset temperature of $24^{0} \mathrm{C}$. The sampling for collection of temperature and power consumption data is 30 minutes for first and the last sample. The same is 15 minutes for rest of the sample.

Table 2. Shows power consumption to maintain temperature at $24^{0} \mathrm{C}$

\begin{tabular}{|c|c|c|c|}
\hline S. No & Time duration & $\begin{array}{c}\text { Temperature } \\
\text { (to maintain constant at } \\
24^{0} \mathrm{C} \text { ) } \\
\text { Room size }\end{array}$ & $\begin{array}{c}\text { Power } \\
\text { Consumption } \\
\text { (in kWh) }\end{array}$ \\
\hline 1 & 12:30 PM to 1:00 PM & $23^{\circ} \mathrm{C}$ to $24^{0} \mathrm{C}$ & .500 \\
\hline 2 & 1:01 PM to1:15 PM & $24^{0} \mathrm{C}$ & .275 \\
\hline 3 & 1:16 PM to $1: 30 \mathrm{PM}$ & $24^{0} \mathrm{C}$ & .200 \\
\hline 4 & 1:31 PM to $1: 45 \mathrm{PM}$ & $24^{0} \mathrm{C}$ & .189 \\
\hline 5 & 1:46 PM to 2:00 PM & $24^{0} \mathrm{C}$ & .189 \\
\hline \multirow[t]{2}{*}{6} & 2:01 PM 2:30 PM & $24^{\circ} \mathrm{C}$ & .290 \\
\hline & & & $1.643 \mathrm{~kW}$ \\
\hline
\end{tabular}

\section{Conclusion}

From above discussion, the Saving is calculated as $(1.8 \mathrm{~kW}-1.643 \mathrm{~kW}) / 1.8 \mathrm{~kW}=.0872$ and percentage saving is of 8.72.The heater is maintained at a set temperature of $24^{\circ} \mathrm{C}$ and power consumption is measured for both the ACO-PID controller and conventional heater. For conventional heater, it is assumed that heater is switched ON/OFF as per the requirement of the user and hence the power consumption by the conventional heater is taken to be $2000 \mathrm{~W}$ $200 \mathrm{~W}=1800 \mathrm{~W}$ (the reduction is because of the periodic turning OFF by the user. Hence the power saving is approximately equal to $8.72 \%$. The simulation is done for computing $\mathrm{K}_{\mathrm{P}}, \mathrm{K}_{\mathrm{I}}$ and $\mathrm{K}_{\mathrm{D}}$. These computed constants are applied in the experimental setup for finding out the resultant power saving. Since the simulation and experiment have been performed for different parameters hence no comparison has been shown in this paper.

\section{References}

[1]. Pandharipande, A. , Philips Res., Eindhoven, Netherlands, Shuai Li , "Light-Harvesting Wireless Sensors for Indoor Lighting Control", IEEE Sensors Journal, (Volume:13, Issue: 12 ), Dec. 2013.

[2]. Andru, L., Valentin, P. , "Hardware design of a street lighting control system with vehicle and malfunction detection", 8th International Symposium on Advanced Topics in Electrical Engineering (ATEE), May 2013.

[3]. Li Lian, "Wireless dimming system for LED Street lamp based on ZigBee and GPRS", 3rd International Conference on System Science, Engineering Design and Manufacturing Informatization (ICSEM), (Volume:2 ), Oct. 2012.

[4]. Li. Z., Wang Z. ,Zhang. M. , Chen L., Wu C. , Wang Z , “A 2.4 GHz Ultra-Low-Power Current-Reuse CG-LNA With Active $\mathrm{G}_{\mathrm{m}}$-Boosting Technique", IEEE Microwave and Wireless Components Letters, (Issue: 99 ), March 2014.

[5]. Stefan, I. , Elgala, H. ,Haas, H "Study of dimming and LED nonlinearity for ACO-OFDM based VLC systems", IEEE Wireless Communications and Networking Conference (WCNC), April 2012. 
[6]. Ntogari, G. , Kamalakis T., "Combining Illumination Dimming Based on Pulse-Width Modulation With Visible-Light Communications Based on Discrete Multitone", IEEE/OSA Journal of Optical Communications and Networking, (Volume:3 , Issue: 1 ), January 2011.

[7]. Jinsoo Han, "Remote-Controllable and Energy-Saving Room Architecture based on ZigBee Communication", IEEE Transactions on Consumer Electronics, Vol. 55, No. 1, February 2009.

[8]. Ivan Vilović, Nikša Burum, Zvonimir Šipuš and Robert Nađ, "PSO and ACO algorithm applied to location optimization of the WLAN base station", $19^{\text {th }}$ international conference on Applied Electromagnetics and Communications, 2007.

[9]. http://en.wikipedia.org/

[10]. SudipMisra, B. John Oommen, "New Algorithms for Maintaining All-Pairs Shortest Paths", Proceedings of the 10th IEEE Symposium on Computers and Communications (ISCC 2005).

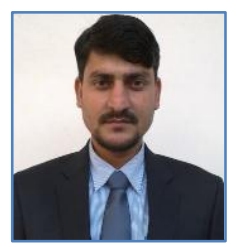

Rajesh Singh is M.Tech (Gold Medalist) in Digital Communication from Rajeev Gandhi Technical University Bhopal, India and received his B.E degree in Electronics \& Communication Engg. from B.R Ambedkar University Agra, India. Currently attached with University of Petroleum and Energy Studies in the Electronics, Instrumentation and Control Engineering department. He has published 40 papers in various national/ international conferences /journals. He won young scientist award in 2012. He has filed 06 patents. He is also the reviewer of many International journals. His area of interest is Zigbee based wireless networks

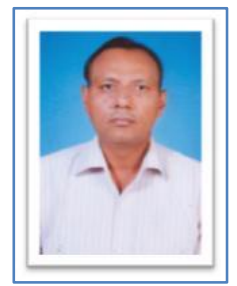

Piyush Kuchhal is B.Sc, from CCS University Meerut, India, Master in Science and Ph.D from India Institute of Technology, Roorkee (IITR). He is working as the Associate Professor and Head of the Department of Physics, University of Petroleum \& Energy studies, Dehradun India. He is having a rich experience of 20 years in the field of semiconductors devices \& physics and published many papers in international journals. His areas of interest includes Semiconductor material \& process, Electronics devices \& Circuits, Optical Communication and Microwave Engineering. 